Z. Klin. Chem. Klin. Biochem.

12. Jg. 1974, S. $159-165$

\title{
Zum Einfluß der Temperatur auf Enzymaktivitätsbestimmungen im Serum: Glutamatdehydrogenase
}

\author{
Von K. Jung, E. Egger, Regina Neumann und Brigitte Lüdtke \\ Aus der Abteilung Klinische Biochemie und dem Lehrstuhl Pathologische Biochemie (Leiter: Prof. Dr. E. Egger) des \\ Bereichs Medizin (Charité) der Humboldt-Universität Berlin
}

(Eingegangen am 5. Oktober 1973/1. März 1974)

\begin{abstract}
Am Beispiel der Glutamatdehydrogenase-Aktivitätsbestimmung des Serums wird das komplexe Zusammenwirken der Meßtemperatur mit den anderen Meßbedingungen dargestellt. Hierzu wurden bei $17,8^{\circ} \mathrm{C}, 25^{\circ} \mathrm{C}, 30^{\circ} \mathrm{C}$ und $37^{\circ} \mathrm{C}$ die Halbsättigungskonstanten bestimmt und die Substratsättigungs- und pH-Kurven aufgenommen. Es konnten temperaturabhängige Veränderungen der Halbsättigungskonstanten für NADH und 2-Oxoglutarat nachgewiesen werden. Zusatz von ADP beseitigt die durch NADH und Ammoniumacetat hervorgerufenen Substrathemmungen. Der besondere Einfluß des pH-Wertes und der Aktivatorenkombination ADP und Leucin auf die Aktivitätsbestimmung der Glutamatdehydrogenase wird anhand von Arrhenius-Auftragungen diskutiert. Unter optimierten Bedingungen der Glutamatdehydrogenase-Aktivitätsbestimmung des Serums konnte eine Denaturierung des Enzyms sowohl in der Vorinkubationsals auch in der Meßzeit bei einer Temperatur von $37^{\circ} \mathrm{C}$ ausgeschlossen werden.
\end{abstract}

\section{The influence of temperature on the determination of enzyme activities in human serum: Glutamate dehydrogenase}

Using the measurement of glutamate dehydrogenase in human serum as an example, the complex interrelations of reaction temperature and other reaction conditions were shown. Half-saturation constants were estimated, and the activity/substrate concentration plots and the activity/pH plots at $17.8^{\circ} \mathrm{C}, 25^{\circ} \mathrm{C}, 30^{\circ} \mathrm{C}$ and $37^{\circ} \mathrm{C}$ were recorded. The pH-optima and half-saturation constants for 2-oxoglutarate and NADH were temperature-dependent. At $37^{\circ} \mathrm{C}$, higher 2-oxoglutarate and NADH concentrations and lower pHvalues than at $25^{\circ} \mathrm{C}$ were necessary for optimal conditions. The addition of ADP abolished the inhibition caused by increased concentrations of NADH ammonium acetate. The important influence of $\mathrm{pH}$ and the activators ADP and $L$-leucine on the glutamate dehydrogenase activity in serum is discussed (Arrhenius-plot). Under optimized conditions the activity of glutamate dehydrogenase in human serum is not altered at $37^{\circ} \mathrm{C}$. It is concluded that for an optimal choice of temperature for enzyme activity determinations in serum, it is very important to take into account the complex relationship between temperature and the other conditions of enzyme reaction.

In der klinischen Chemie werden zur Zeit die meisten Enzymaktivitätsbestimmungen im Serum bei $25^{\circ} \mathrm{C}$, $30^{\circ} \mathrm{C}$ und $37^{\circ} \mathrm{C}$ ausgeführt. Als ein Nachteil der Enzymaktivitätsbestimmungen bei höheren Temperaturen wird unter anderem die Denaturierung bzw. Inaktivierung des Enzyms angesehen (1). Der Nachweis der Denaturierung bzw. Inaktivierung eines Enzyms bei höheren Meßtemperaturen ist nach unserer Ansicht erst dann exakt möglich, wenn berücksichtigt wird, daß bei unterschiedlichen Temperaturen die optimalen Werte der anderen Meßbedingungen verschieden sein können. So zeigte Szasz (2), daß die Affinität der Enzyme zu ihren Substraten temperaturabhängig ist. Im allgemeinen sind die komplexen Beziehungen zwischen Meßtemperatur und den anderen Reaktionsbedingungen bisher nur wenig untersucht worden. In der vorliegenden Arbeit wird am Modellbeispiel der Glutamatdehydrogenase (EC 1.4.1.3), bei der auf Grund ihrer allosterischen Eigenschaften eine besondere Temperaturempfindlichkeit anzunehmen ist (3), die gegenseitige Beeinflussung der Meßbedingungen bei verschiedenen Temperaturen dargestellt.

\section{Methoden und Material}

Die Enzymaktivitätsbestimmungen erfolgten am EppendorfPhotometer bei $366 \mathrm{~nm}$ in kontinuierlicher Messung mit Schreiber. Die Temperatur im Bestimmungsansatz wurde im temperierten Küvettenhalter über einen Umlaufthermostaten mit Wasserkühlung (Typ U 10, VEB Prüfgerätewerk Medingen: Wasserinhalt 121 , Umwälzgeschwindigkeit $61 / \mathrm{min}$ ) konstant gehalten. Die Temperatur im Thermostaten wurde durch ein Kontaktthermometer geregelt und in der Küvette ständig mit einem geeichten Quecksilberthermometer mit geringer Masse bzw. mit einem Thermistor kontrolliert. Das Thermometer war mit einem auf $1 / 100^{\circ} \mathrm{C}$ geeichten Thermometer nachgeeicht worden. Die Genauigkeit der Temperaturmessung und die Temperaturkonstanz in der Meßküvette wurden durch eingehende Überprüfungen durch Widerstandsmessungen mit einem geeichten Thermistor und dem MultiFunction Meter 3450 B von Hewlett-Packard überprüft, wobei das zuletzt genannte Gerät jedoch nicht ständig zur Verfügung stand. Auf diese Weise wurde gesichert, daß die Abweichungen von der Solltempcratur bzw. die Temperaturschwankungen im Zeitablauf nicht mehr als $\pm 0,07^{\circ} \mathrm{C}$ betrugen. Die angegebenen Aktivitäten entsprechen den aus Doppelbestimmungen gemittelten Umsätzen in der ersten Minute des Linearteils unter Berücksichtigung des unspezifischen Vorlaufs. Das Untersuchungsmaterial wurde zur Erreichung der Temperaturkonstanz etwa 10 bis 15 min vorinkubiert. Aus den Doppelbestimmungen wurde die Standardabweichung $s$ in der Serie (Aktivitäten von 14,4 bis $94,4 \mathrm{U} / \mathrm{l}$ ) entsprechend der Formel $s=\sqrt{ } \frac{\Sigma R^{2}}{2 m}(R=$ Differenz der Doppel- 
bestimmungen, $\mathrm{m}=$ Anzahl der Doppelbestimmungen) zu 1,6 bis $2,7 \mathrm{U} / 1$ bei den niederen bzw. höheren Aktivitäten errechnet.

Die Endkonzentrationen im Testansatz von $1,5 \mathrm{ml}$ betrugen, wenn nicht anders erwähnt: $50 \mathrm{mmol} / 1$ Triäthanolaminhydrochlorid, $\mathrm{pH} 7,6,125 \mathrm{mmol} / 1$ Ammoniumacetat, $1 \mathrm{mmol} / 1$ Dinatriumäthylendiamintetraacetat, $12 \mathrm{mmol} / 12$-Oxoglutarat, $0,3 \mathrm{mmol} / 1 \mathrm{NADH}$ und $1 \mathrm{mmol} / \mathrm{l} \mathrm{ADP}(4)$. Das Verhältnis von Serum zum Gesamtvolumen betrug 1:7,5. Gestartet wurde mit 2-Oxoglutarat, das bei der jeweiligen Meßtemperatur vorinkubiert wurde.

Der pH-Wert der Puffer-Substrat-Gemische wurde, da Triäthanolamin ein deutlich temperaturabhängiger Puffer ist, für die jeweilige Temperatur potentiometrisch eingestellt. Als Eichpuffer dienten Standardpufferlösungen, die nach den Angaben des National Bureau of Standards bereitet wurden.

Die thermische Stabilität der Glutamatdehydrogenase wurde bei $25^{\circ} \mathrm{C}, 37^{\circ} \mathrm{C}$ und $56^{\circ} \mathrm{C}$ geprüft. Hierzu wurde bei den angegebenen Temperaturen unter den im Ergebnisteil näher aufgeführten Bedingungen Serum inkubiert, nach einer vorgegebenen Zeit ein Aliquot entnommen, im Eisbad gekühlt und anschließend im LKB Reaction Rate Analyzer 8600 bei $37^{\circ} \mathrm{C}$ die Aktivität bestimmt.

Die verwendeten Chemikalien waren analysenrein; die Biochemikalien wurden von der Fa. C. F. Boehringer GmbH, Mannheim bezogen. Als Untersuchungsmaterial verwendeten wir gepooltes Serum von Patienten bzw. mit menschlicher Glutamatdehydrogenase angereicherte Seren. Die Glutamatdehydrogenase wurde nach Lehmann und Pfleiderer (5) aus Humanleber präpariert (spezifische Aktivität 8,6 U/mg Protein). ADP wurde mit dem Boehringer-Testbesteck bestimmt, NADH bei $366 \mathrm{~nm}$ gemessen und der Berechnung ein Extinktionskoeffizient von $3,3 \cdot 10^{6} \mathrm{~cm}^{2} / \mathrm{mol}$ zugrunde gelegt.

Die Signifikanzprüfung der Unterschiede der Halbsättigungskonstanten erfolgte als Signifikanzprüfung der Unterschiede in den Steigungen der jeweiligen Regressionsgeraden, die sich aus der Auftragung von v gegen $\frac{v}{r}$ ergaben.

$$
\text { [S] }
$$

\section{Ergebnisse}

Temperaturabhängigkeit der $\mathrm{Halbsättigungs-}$ konstanten der Glutamatdehydrogenase des Serums

In Abhängigkeit von der Temperatur wurden die Halbsättigungskonstanten der Glutamatdehydrogenase für die Substrate $\mathrm{NH}_{4}^{+}, 2-\mathrm{Oxoglu}$ tarat und $\mathrm{NADH}$ bestimmt und die entsprechenden Substratsättigungskurven aufgenommen (Tab. 1, Abb. 1 bis 3).

Die Halbsättigungskonstanten wurden aus der Regressionsgeraden in der Auftragung v gegen $\frac{v}{[S]}$ als negativer Anstieg ermittelt (6). Diese Auftragung wurde gewählt, da die auf diese Weise errechneten Halbsättigungskonstanten ein kleines Vertrauensintervall haben (7) und es mit dieser Methode möglich ist, mit relativ geringem rechentechnischem Aufwand Signifikanzprüfungen durchzuführen.

Die Halbsättigungskonstante für Ammoniumacetat erscheint durch die Temperatur unbeeinflußt. Die Halbsättigungskonstante für NADH im Testansatz ohne ADP nimmt mit steigender Temperatur ab $(p<0,05)$. Mit ADP, d. $h$. im sogenannten aktivierten Test, erhöht sich dagegen die Halbsättigungskonstante für NADH $(p<0,05)$. Ein Vergleich der Konstanten mit und ohne ADP-Zusatz bei gleichen Temperaturen zeigt für
2-Oxoglutarat bei $25^{\circ} \mathrm{C}$ und $37^{\circ} \mathrm{C}$ und für NADH bei $30^{\circ} \mathrm{C}$ und $37^{\circ} \mathrm{C}$ mit ADP signifikante Erhöhungen

$(\dot{\mathrm{p}}<0,05)$.

Die dargestellten Substratsättigungskurven (Abb. 1,2) verdeutlichen, daß der Zusatz von ADP die durch Ammoniumacetat und NADH bedingten Substrathemmungen aufhebt. Die Hemmung der Glutamatdehydrogenase

Tab. 1. Halbsättigungskonștanten der Glutamatdehydrogenase des Serums unter aktivierten und nichtaktivierten Bedingungen in Abhängigkeit von der Meßtemperatur Die Daten wurden unter den im methodischen Teil angegebenen Bedingungen ermittelt. 2-Oxoglutarat wurde von 0,2 bis $2 \mathrm{mmol} / \mathrm{l}$, Ammoniumacetat von 2,5 bis $20 \mathrm{mmol} / \mathrm{l}$ und $\mathrm{NADH}$ von $0,014 \mathrm{bis} 0,1 \mathrm{mmol} / 1$ unter Berücksichtigung des unspezifischen NADH-Verbrauchs in der Vorinkubation variiert. Errechnung der Halbsättigungskonstanten aus dem negativen Änstieg in der Auftragung von $v$ gegen $\frac{v}{[S]}$. Angabe der Halbsättigungskonstanten in $\mathrm{mmol} / 1$.

\begin{tabular}{|c|c|c|c|c|c|c|}
\hline $\begin{array}{l}\text { Tempe- } \\
\text { ratur } \\
{ }^{\circ} \mathrm{C}\end{array}$ & $\begin{array}{l}\text { Ammo } \\
\text { ohne } \\
\text { ADP }\end{array}$ & $\begin{array}{l}\text { niumacetat } \\
\text { mit } \\
\text { ADP }\end{array}$ & $\begin{array}{l}\text { Oxogl } \\
\text { ohne } \\
\text { ADP }\end{array}$ & $\begin{array}{l}\text { rat } \\
\text { mit } \\
\text { ADP }\end{array}$ & $\begin{array}{l}\text { NADH } \\
\text { ohne } \\
\text { ADP }\end{array}$ & $\begin{array}{l}\text { mit } \\
\text { ADP }\end{array}$ \\
\hline $\begin{array}{l}17,8 \\
25 \\
30 \\
37\end{array}$ & $\begin{array}{l}23,9 \\
14,0 \\
19,0 \\
19,5\end{array}$ & $\begin{array}{l}26,9 \\
24,9 \\
19,2 \\
18,9\end{array}$ & $\begin{array}{l}0,738 \\
0,688 \\
0,620 \\
0,762\end{array}$ & $\begin{array}{l}0,776 \\
1,16 \\
1,04 \\
1,28\end{array}$ & $\begin{array}{l}0,085 \\
0,079 \\
0,037 \\
0,048\end{array}$ & $\begin{array}{l}0,063 \\
0,077 \\
0,081 \\
0,142\end{array}$ \\
\hline
\end{tabular}
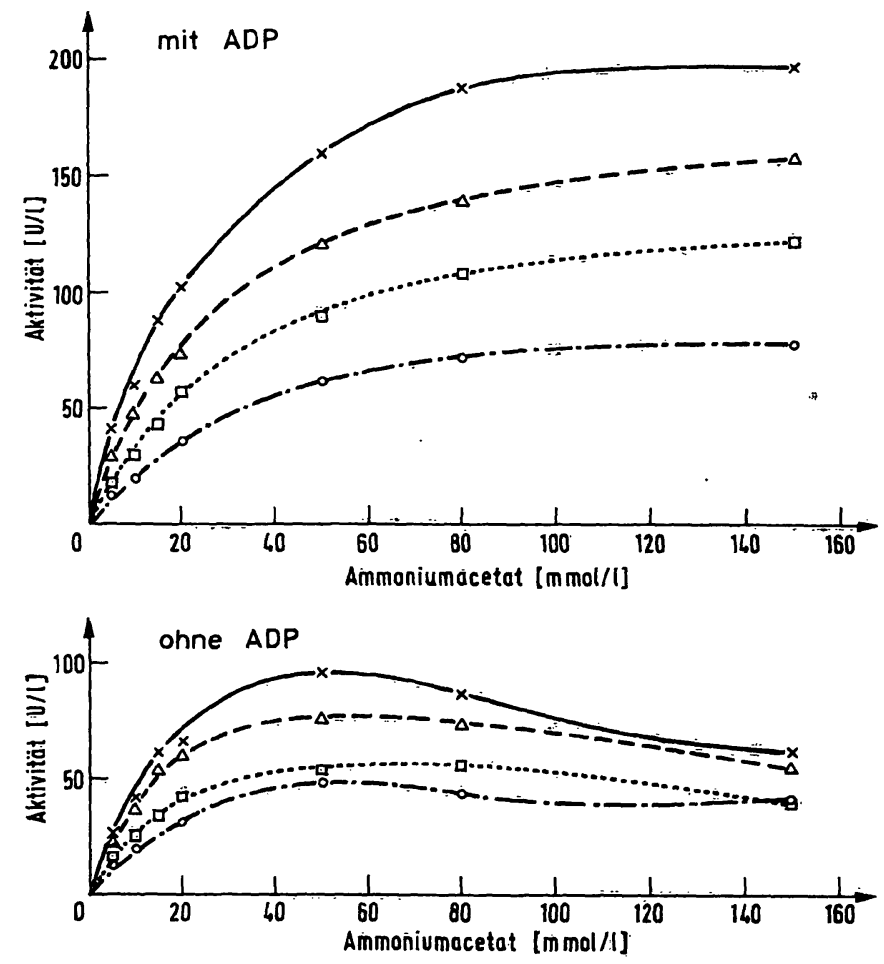

Abb. 1. Einfluß der Meßtemperatur auf die Substratsättigung der Glutamatdehydrogenase für Ammoniumacetat mit und ohne Aktivatorzusatz

Meß̉bedingungen: s. Methodik, Aktivierung mit $1 \mathrm{mmol} / 1$

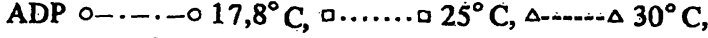
$\mathrm{x}-\mathrm{x} 37^{\circ} \mathrm{C}$. 

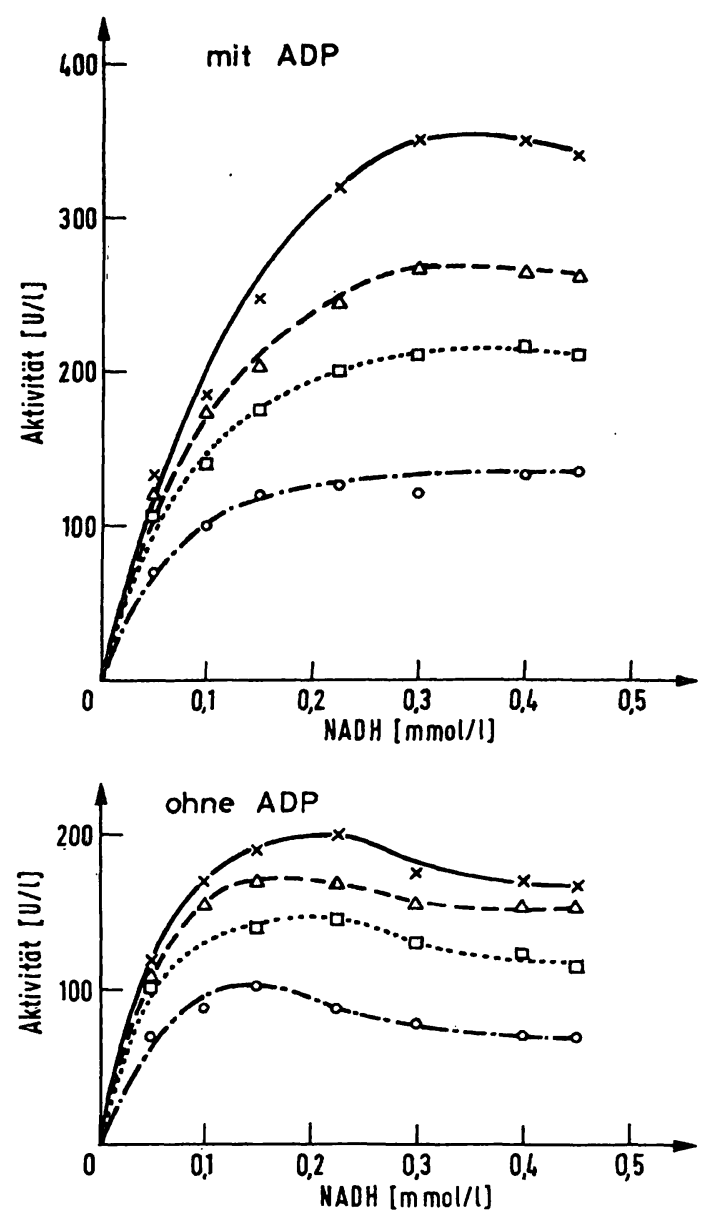

Abb. 2. Einfluß der Meßtemperatur auf die Substratsättigung der Glutamatdehydrogenase für NADH mit und ohne Aktivatorzusatz

Meßbedingungen und Symbole: s. Abb. 1.

durch Ammoniumacetat wird im nichtaktivierten Test bei höheren Meßtemperaturen verstärkt. Die von Schmidt und Schmidt (8) angegebene Hemmung durch 2-Oxoglutarat konnte in dieser ausgeprägten Form jedoch nicht bestätigt werden (Abb. 3).

Einfluß von $\mathrm{pH}$ und Aktivatoren auf die Glutamatdehydrogenase-Ak tivität des Serum s

Triäthanolamin-Puffer wird als der für Glutamatdehydrogenase-Aktivitätsbestimmungen im Serum günstigste Puffer angesehen $(4,9,10)$. Der optimale pH-Wert wird für $25^{\circ} \mathrm{C}$ mit pH 8,0 (10), für $37^{\circ} \mathrm{C}$ mit 7,4 (11) bzw. $7,6(4)$ angegeben. Schon in einer vorhergehenden Mitteilung (4) wiesen wir daraufhin, daß ein $\mathrm{pH}$ von 8,0 bei $37^{\circ} \mathrm{C}$ sich als ungünstig erweist, wenn nicht mit Aktivatorzusatz gemessen wird. Das pH-Optimum verschiebt sich bei Erhöhung der Meßtemperatur in Richtung zu niedrigeren pH-Werten (Abb. 4). Dies gilt für Meßbedingungen mit ADP-Zusatz, wird aber besonders deutlich bei Aktivitätsbestimmungen ohne ADP.Zusatz. Im zweiten Fall liegt z. B. die bei $37^{\circ} \mathrm{C}$, pH 8,0 gemessene Aktivität unter der bei $17,8^{\circ} \mathrm{C}$ bestimmten. Unter diesen Bedingungen kommt es zur Denaturierung der Glutamatdehydrogenase in der Vorinkubationszeit
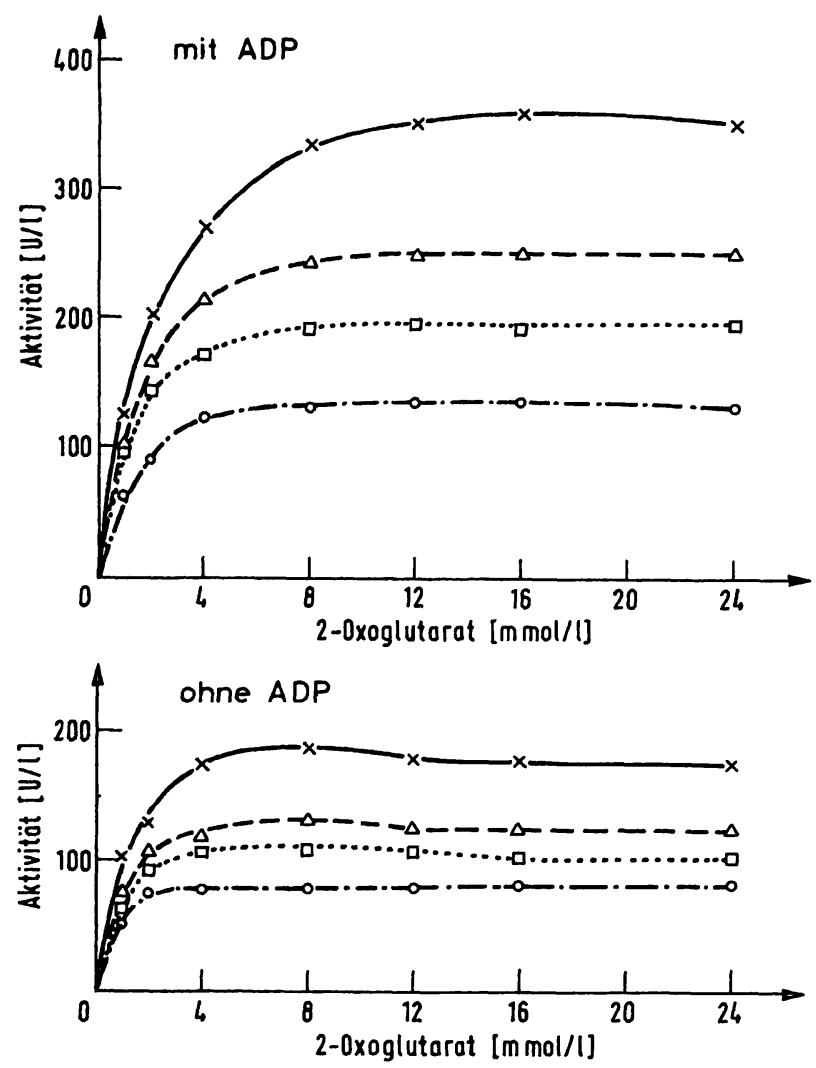

Abb. 3. Einfluß der Meßtemperatur auf die Substratsättigung der Glutamatdehydrogenase für 2-Oxoglutarat mit und ohne Aktivatorzusatz

Meßbedingungen und Symbole: s. Abb. 1.

(Tab. 2). Ohne Aktivatorzusatz wird in Abhängigkeit von der Vorinkubationszeit eine stetige Aktivitätsabnahme beobachtet, die auch durch Zusatz von ADP und Leucin $1 \mathrm{~min}$ vor dem Start mit 2-Oxoglutarat nicht voll reversibel ist. Eine Denaturierung des Enzyms ist daher anzinehmen.

In Abhängigkeit von der Temperatur hat auch die verwendete Pufferkonzentration erheblichen Einfluß auf die gemessene Aktivität. Während bei höheren Triäthanolaminkonzentrationen ohne Zusatz von ADP unabhängig von der Temperatur eine Stimulierung zu beobachten ist, wird der durch Effektoren bedingte Aktivierungseffekt besonders bei höheren Meßtemperaturen beein-

Tab. 2. Denaturierung der Glutamatdehydrogenase bei $\mathrm{pH}$ 8,25 in Abhängigkeit von der Vorinkubationszeit Meßbedingungen: s. Methodik, Temperatur $37^{\circ} \mathrm{C}$. Als Zusatz diente $1 \mathrm{mmol} / 1 \mathrm{ADP}+10 \mathrm{mmol} / 1 \quad L$-Leucin. Der Zusatz von ADP und Leucin erfolgte $1 \mathrm{~min}$ vor dem Start mit 2-Oxoglutarat. Angabe der ermittelten Aktivitäten in $U / 1$.

\begin{tabular}{llll}
\hline $\begin{array}{l}\text { Vorinkubation } \\
\text { min }\end{array}$ & $\begin{array}{l}\text { mit Zusatz in } \\
\text { Vorinkubation }\end{array}$ & $\begin{array}{l}\text { mit Zusatz nach } \\
\text { Vorinkubation }\end{array}$ & ohne Zusatz \\
\hline 5 & 96,6 & 56,2 & 22,5 \\
10 & 98,5 & 52,3 & 20,0 \\
20 & 101,5 & 28,1 & 16,2 \\
30 & 97,5 & 23,1 & 10,0 \\
40 & 95,0 & 17,2 & 11,7 \\
60 & 96,3 & 20,6 & 8,8 \\
\hline
\end{tabular}



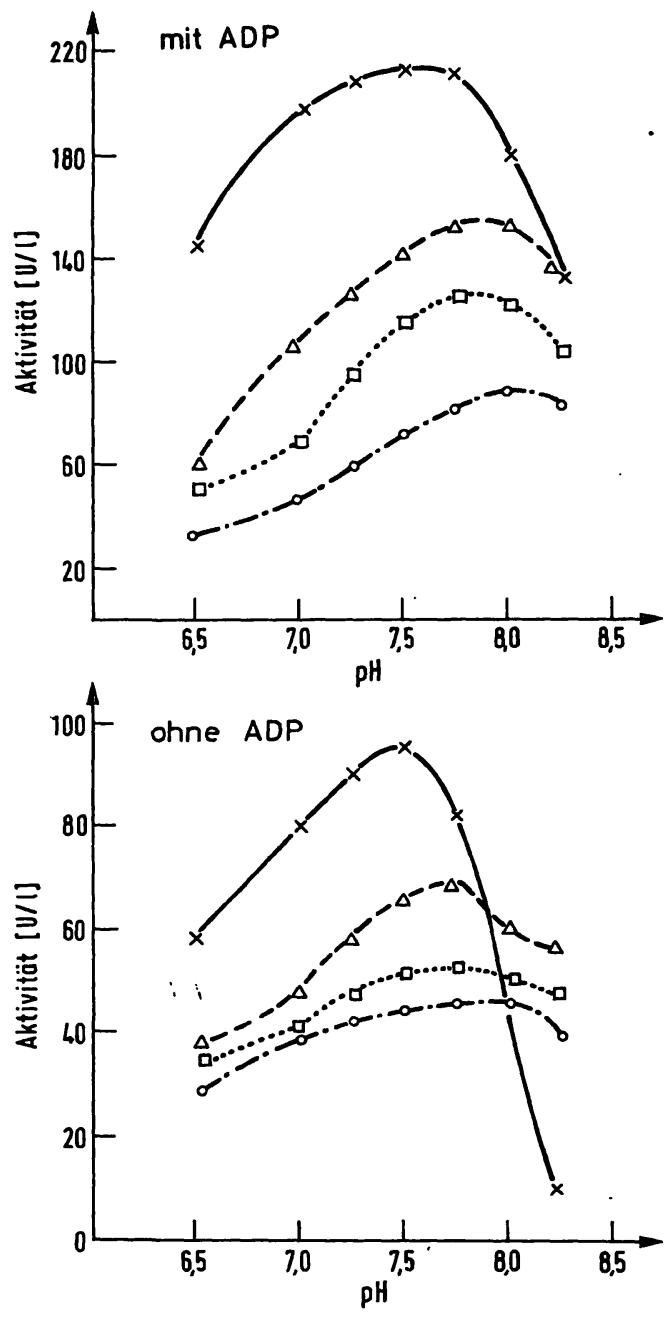

Abb. 4. Einfluß der Meßtemperatur auf die pH-Kurven der Glutamatdehydrogenase-Aktivität mit und ohne Aktivatorzusatz

Meßbedingungen und Symbole: s. Abb. 1.

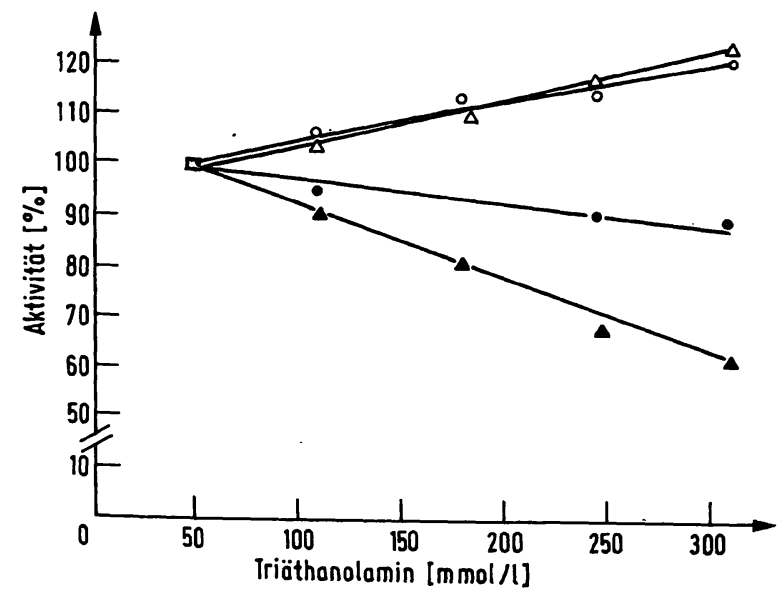

Abb. 5. Einfluß der Pufferkonzentration auf die Glutamatdehydrogenase-Aktivität in Abhängigkeit von der Meßtemperatur mit und ohne Aktivatorzusatz $\circ \longrightarrow{ }^{\circ} 17,8^{\circ} \mathrm{C}$, $\Delta-\Delta 37^{\circ} \mathrm{C}$. Leere Symbole: ohne Aktivatorzusatz, gefullte Symbole: $0,4 \mathrm{mmol} / 1 \mathrm{ADP}+10 \mathrm{mmol} / 1 \mathrm{~L}$-Leucin als Aktivatorzusatz. trächtigt (Abb. 5). Aus diesem Grunde ist für eine optimierte Methode der Glutamatdehydrogenase-Aktivitätsbestimmung sowohl bei $25^{\circ} \mathrm{C}$ als auch bei $37^{\circ} \mathrm{C}$ $(4,9)$ eine Pufferkonzentration von $50 \mathrm{mmol} / 1$ Triäthanolaminhydrochlorid vorgeschlagen worden.

\section{Arrhenius-Auftragungen}

Aus den vorgenannten Untersuchungen 'ergibt sich der besondere Einfluß des $\mathrm{pH}$ und der Aktivatoren im Meßansatz auf die Glutamatdehydrogenase-Aktivitätsbestimmung in Abhängigkeit von der Temperatur. Dies verdeutlicht die Arrhenius-Auftragung der Glutamatdehydrogenase-Aktivität unter verschiedenen $\mathrm{pH}-\mathrm{Be}$ dingungen (Abb. 6). Bei höheren Temperaturen wird ein deutlicher Knick im Arrhenius-Diagramm beobachtet, wenn ohne Aktivatorzusatz gearbeitet wird. Dieser Knick ist auch im Meßansatz bei pH 8,0 und pH 8,25 unter ADP- und Leucin-Zusatz nicht $\mathrm{zu}$ beseitigen. Eine Gerade wird jedoch bei pH 7,6 mit ADP und Leucin in Kombination erreicht.
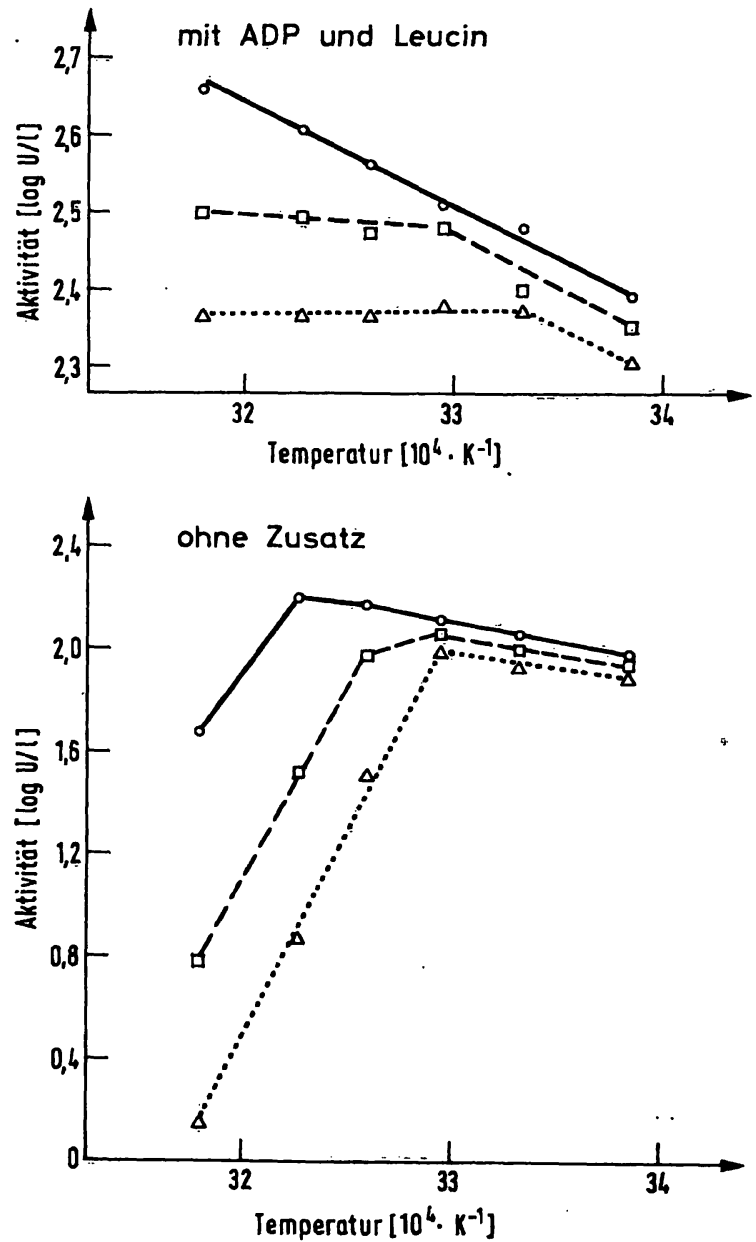

Abb. 6. Einfluß des pH-Wertes auf die Arrhenius-Auftragung für die Glutamatdehydrogenase-Aktivität mit und ohne Aktivatorzusatz

Die verwendeten Substratkonzentrationen entsprachen den im methodischen Teil angegebenen, die Aktivierung wurde durch $1 \mathrm{mmol} / 1 \mathrm{ADP}+\boldsymbol{L}$-Leucin erzeilt.

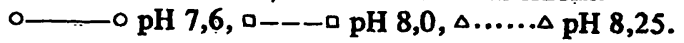




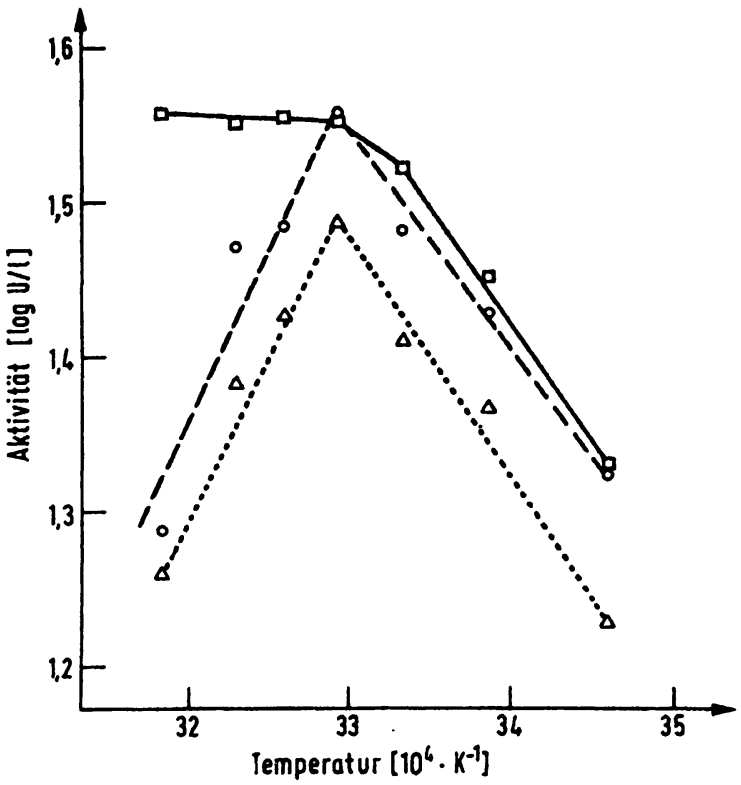

Abb. 7. Einfluß der Aktivatoren ADP und $L$-Leucin auf die Arrhenius-Auftragung für die GlutamatdehydrogenaseAktivität unter ungünstigen Reaktionsbedingungen Meßbedingungen: s. Methodik, $\mathrm{pH}$ des Meßansatzes $\mathrm{pH}$ $8,25 . \Delta \ldots \ldots \Delta 10 \mathrm{mmol} / 1 \mathrm{~L}$-Leucin, 0 - $01 \mathrm{mmol} / 1 \mathrm{ADP}$, $\square \longrightarrow$ ADP + L-Leucin

Von uns wurde für einen optimierten Test zur Glutamatdehydrogenase-Aktivitätsbestimmung im Serum die Kombination ADP und Leucin vorgeschlagen (4). Der Vorteil dieser Effektorenkombination liegt nicht nur in der erhöhten Aktivierung und dem verringerten ADP-Bedarf, sondern auch in der besonders hohen Schutzwirkung bei ungünstigen Meßbedingungen. Der unterschiedliche Schutzeffekt der einzelnen Aktivatoren bzw. ihrer Kombination wird deutlich bei ungünstigem $\mathrm{pH}$ im Testansatz (Abb. 7). Dies ist ein weiterer Hinweis auf die von anderen Autoren (12) angenommenen unterschiedlichen Angriffspunkte der beiden Aktivatoren auf das GlutamatdehydrogenaseMolekül.

\section{Thermische Stabilität der Glutam atdehydroge-} nase

Im Meßansatz ohne Zusatz von Aktivatoren fiel während einer zweistündigen Vorinkubation bei $37^{\circ} \mathrm{C}$ die Aktivität auf $80 \%$ der Ausgangsaktivität ab. Dieser Abfall wurde unter gleichen Bedingungen auch bei $25^{\circ} \mathrm{C}$ beobachtet. Durch Zusatz von ADP und Leucin zum Meßansatz bei sonst optimalen Bedingungen (4) wurde dagegen in der genannten Zeit bei $37^{\circ} \mathrm{C}$ eine Inaktivierung der Glutamatdehydrogenase verhindert. Selbst unter den extremen Bedingungen von $56^{\circ} \mathrm{C}$ war im Serum innerhalb von 60 min keine Aktivitätsminderung festzustellen (Abb. 8). Mit nur einem Aktivator bzw. ohne Aktivator erfolgt die Inaktivierung jedoch rasch und beinahe vollständig. Die thermische Stabilität der Glutamatdehydrogenase im Meßansatz ist weitgehend vom Proteingehalt der Probe unbeeinflußt.

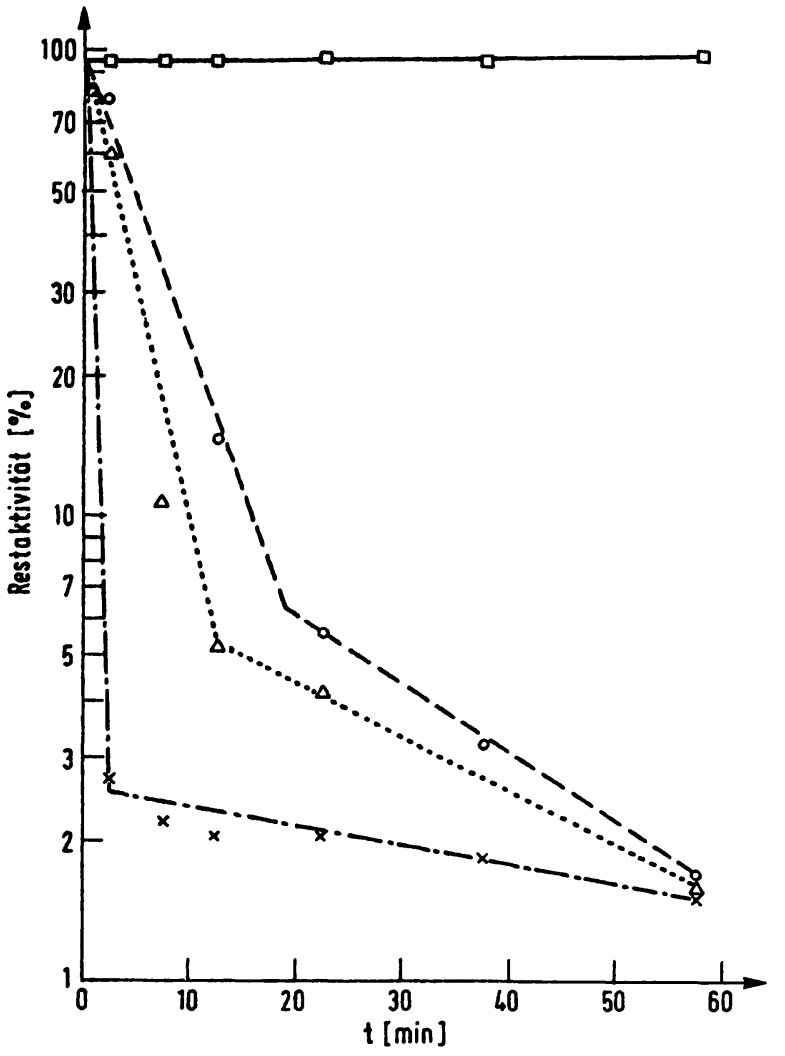

Abb. 8. Einfluß der Aktivatoren ADP und $L$-Leucin auf die Hitzestabilität der Glutamatdehydrogenase im Serum bei $56^{\circ} \mathrm{C}$ $0,5 \mathrm{ml}$ Serum wurden mit $0,1 \mathrm{ml}$ dest. Wasser $\mathrm{x}-\cdot-\cdot-\mathrm{x}$, mit $0,05 \mathrm{ml} 10 \mathrm{mmol} / 1 \mathrm{ADP}+0,05 \mathrm{ml}$ dest. Wasser $0---0$, mit $0,05 \mathrm{ml} 100 \mathrm{mmol} / 1 \mathrm{~L}$-Leucin $+0,05 \mathrm{ml}$ dest. Wasser $\Delta-.----\Delta$ und mit $0,05 \mathrm{ml} 10 \mathrm{mmol} / 1 \mathrm{ADP}$ $+0,05 \mathrm{ml} 100 \mathrm{mmol} / 1 \mathrm{~L}$-Leucin $\square \longrightarrow$ o versetzt, entsprechende Zeit bei $56^{\circ} \mathrm{C}$ inkubiert und anschließend unter den im methodischen Teil angegebenen Bedingungen am LKB Reaction Rate Analyzer 8600 bei $37^{\circ} \mathrm{C}$ bestimmt.

Ein 30 fach verdünntes Serum (Protein $73 \mathrm{~g} / 1$ ) zeigte bei einstündiger Vorinkubation bei $37^{\circ} \mathrm{C}$ im genannten Meßansatz mit ADP- und Leucin-Zusatz keinen Aktivitätsabfall.

\section{Diskussion}

Ein entscheidendes Problem bei der Standardisierung von Enzymaktivitätsbestimmungen im Serum ist die $\mathrm{zu}$ wählende Meßtemperatur. Als Temperaturen werden $25^{\circ} \mathrm{C}, 30^{\circ} \mathrm{C}$ und $37^{\circ} \mathrm{C}$ vorgeschlagen (13). Als ein Nachteil der Enzymaktivitätsbestimmungen bei höheren Meßtemperaturen wird u. a. die Denaturierung bzw. Inaktivierung des Enzymproteins angesehen (1). Kürzlich konnte mit für $25^{\circ} \mathrm{C}$ optimierten Methoden gezeigt werden, daß bei Meßtemperaturen über $30^{\circ} \mathrm{C}$ die Transaminasen (EC 2.6.1.1 und EC 2.6.1.2), die Kreatinkinase (EC 2.7.3.2) und die Lactatdehydrogenase-Isoenzyme (EC 1.1.1. 27) im Arrhenius-Diagramm von der Linearität abweichen (2). Unter Berücksichtigung der temperaturabhängigen Substratsättigung wiesen Ellis und Goldberg (14) jedoch für die LDH-1 als Hydroxybutyratdehydrogenase in der Arrhenius- 
Auftragung eine Gerade bis $37^{\circ} \mathrm{C}$ nach. Dies zeigt eindeutig, wie wichtig es ist, die temperaturabhängigen optimalen Reaktionsbedingungen eines Enzyms zu kennen, um seine Denaturierung bei höheren Meßtemperaturen exakt nachweisen zu können. Für die meisten Enzyme im Serum fehlen bisher entsprechende experimentelle Untersuchungen, die den komplexen Charakter des Einflusses der Temperatur im Zusammenhang mit den anderen Meßbedingungen auf Enzymaktivitätsbestimmungen berücksichtigen.

Die von uns unter vergleichbaren Bedingungen ermittelten Halbsättigungskonstanten der Glutamatdehydrogenase für Ammoniumacetat und 2-Oxoglutarat entsprechen etwa den von Lehmann und Pfleiderer (5) angegebenen $\mathrm{K}_{\mathrm{m}}$-Werten der Glu tamatdehydrogenase aus Humanleber. Die Halbsättigungskonstanten für NADH und 2-Oxoglutarat zeigen jedoch temperaturabhängige Veränderungen. Auffällig ist hierbei, daß im nichtaktivierten Test die Halbsättigungskonstante für NADH mit steigender Temperatur abnimmt, dagegen im Meßansatz mit ADP-Zusatz ansteigt. Dies dürfte auf Veränderungen der allosterischen Eigenschaften der Glutamatdehydrogenase hinweisen, die auf das komplexe Zusammenwirken von Temperatur, NADH und ADP zurückzuführen sind.

Verschiedentlich wurden in der Vergangenheit die Substratkonzentrationen für Enzymaktivitätsbestimmungen auf Grund der $\mathrm{K}_{\mathrm{m}}$-Werte festgelegt. Erst kürzlich empfahlen Deggeller und Sandifort (15), die optimale Substratkonzentration entsprechend dem 20 fachen $K_{m}$-Wert zu wählen. Bei der Erarbeitung optimierter Methoden von Enzymaktivitätsbestimmungen darf jedoch nicht nur die Halbsättigungskonstante bzw. der $\mathrm{K}_{\mathrm{m}}$-Wert ausschlaggebend für die Wahl der Substratkonzentration sein. Zur Festlegung der zweckmäßigen Substratkonzentration ist die Aufnahme vollständiger Substratsättigungskurven nach Michaelis-Menten unerläßlich, da sonst eventuell auftretende Substrathemmungen nicht berücksichtigt würden. Die Berechtigung dieser Forderung läßt sich am Beispiel der Glutamatdehydrogenase im nichtaktivierten Test für die Substrate Ammoniumacetat und NADH erhärten. Im aktivierten Test, der sich weitgehend durchgesetzt hat, ist keine Substrathemmung mehr festzustellen, dagegen ist zu beachten, daß die optimalen Substratkonzentrationen für NADH und 2-Oxoglutarat für $37^{\circ} \mathrm{C}$ höher als für $25^{\circ} \mathrm{C}$ liegen.
Der besondere Einfluß des pH-Wertes auf die Glutamatdehydrogenase-Aktivität in Abhängigkeit von der Meßtemperatur steht im engen Zusammenhang mit dem kooperativen Verhalten dieses Enzyms. Die nachgewiesene Denaturierung des Enzyms unter ungünstigem $\mathrm{pH}$ bei höherer Meßtemperatur findet hierin ịhre Erklärung. Dieses Beispiel zeigt wiederum, daß die Anwendung der Arrhenius-Auftragung zum Na'chweis einer Denaturierung oder Inaktivierung eines Enzyms nur dann sinnvoll ist, wenn die für die untersuchten Temperaturen optimalen Reaktionsbedingungen Berücksichtigung finden. Andererseits kann eine Diskontinuität im Arrhenius-Diagramm als Ausdruck des Übergangs von einer Aktivierungsenergie zur anderen vielfältiger Natur sein (16). Besonders bei allosterischen Enzymen ist eine solche Diskontinuität nicht unbedingt und in jedem Fall als thermische Denaturierung zu deuten. So wurde bei der Isocitratdehydrogenase (EC 1.4.1.42) von Hefe bei $10^{\circ} \mathrm{C}$ eine Diskontinuität im ArrheniusDiagramm beschrieben (17). Um eine eventuell stattfindende thermische Denaturierung des Enzyms zu erkennen, ist es erforderlich, den Denaturierungseffekt der Temperatur ânhand gestaffelter Vorinkubations- und Meßzeiten zu erfassen. Da bei der Glutamatdehydrogenase eine zweistündige Vorinkubation von Seren im Meßansatz unter Aktivatorzusatz bei $37^{\circ} \mathrm{C}$ nicht zur Aktivitätseinbuße führt, ist für dieses Ënzym eine Denaturierung bei dieser Temperatur unter optimierten Meßbedingungen nicht anzunehmen. Innerhalb einer Meßzeit von 5 min zeigt die Reaktion einen linearen Verlauf (4), sobald gewährleistet wird, daß der NADH-Sättigungsbereich nicht verlassen wird. Damit kann auch eine während der ablaufenden Reaktion stattfindende Denaturierung des Enzyms ausgeschlossen werden. Unter optimierten Bedingungen ist es also möglich, die Glutamatdehydrogenase des Serums auch bei $37^{\circ} \mathrm{C}$ zu bestimmen, ohne eine Denaturierung des Enzyms befürchten zu müssen.

Wir glauben somit am Beispiel der Glutamatdehydro-* genase im Serum gezeigt zu haben, daß bei allen Untersuchungen zum Für und Wider hinsichtlich einer bestimmten Standardtemperatur bzw. der optimalen Temperatur für Enzymaktivitätsbestimmungen im Serum das komplexe Zusammenwirken verschiedener Faktoren mit der Temperatur unbedingt berïcksichtigt werden muß.

\section{Literatur}

1. Bergmeyer, H. U. (1973), diese Z. 11, 39-45.

2. Szasz, G. (1972), 8. Internationaler Kongreß Klinische Chemie, Kopenhagen.

3. Reisler, E. \& Eisenberg, H. (1971), Biochemistry 10, 。 2659-2662.

4. Jung, K., Sokolowski, A. \& Egger, E. (1972/73), Enzyme $14,44-54$.
5. Lehmann, F. G. \& Pfleiderer, G. (1969), Hoppe-Seyler's Z. Physiol. Chem. 350, 609-616.

6. Augustinsson, K.-B. (1948), Acta Physiol Scand. 15, Suppl. 52, zitiert in: Dixon, M. \& Webb, E. C. (1959), Enzymes, Longman \& Co., London, S. 21.

7. Dowd, J. E. \& Riggs, D. S. (1965), J. Biol. Chem. 240, 863-869. 
8. Schmidt, E. \& Schmidt, F. W. (1962), Klin. Wochenschr. 40, 962-969.

9. Ellis, G. \& Goldberg, D. M. (1972), Clin. Chim. Acta 39, 472-474.

10. Empfehlungen der Dtsch. Ges. Klin. Chem. (1972), diese Z. $10,182-192$.

11. Ellis, G. \& Goldberg, D. M. (1972), Clin. Chem. 18, 523527.

12. Markau, K. \& Steinhübel, I. (1972), FEBS Letters 28, 115120.
13. I. F. C. C. Reference Methods for Enzymes, Draft Proposal No. 8.

14. Ellis, G. \& Goldberg, D. M. (1971), Amer. J. Clin. Pathol. $56,627-635$.

15. Deggeller, K. \& Sandifort, C. R. J. (1973), Clin. Chim. Acta 43, 13-22.

16. Dixon, M. \& Webb, E. C. (1964), Enzymes, Longman \& Co., London, S. $158 \mathrm{ff}$.

17. Palm, D. \& Katzendobler, H. (1972), Biochemistry 11, 1283-1289.
Dr. K. Jung, Prof. Dr. E. Egger,

Regina Neumann und Brigitte Lüdtke,

Abteilung Klinische Biochemie

des Bereichs Medizin (Charité)

und Lehrstuhl für Pathologische Biochemie

der Humboldt-Universität Berlin,

104 Berlin, Schumannstraße 